\title{
Access to care among Medicaid and uninsured patients in community health centers after the Affordable Care Act
}

\author{
Veri Seo ${ }^{1}$, Travis P. Baggett ${ }^{2,3,4}$, Anne N. Thorndike ${ }^{2,3}$, Peter Hull ${ }^{5}$, John Hsu ${ }^{1,3,6}$, Joseph P. Newhouse $e^{6,7,8}$
} and Vicki Fung ${ }^{1,3^{*}}$ (D)

\begin{abstract}
Background: The Affordable Care Act expanded Medicaid and increased federal funding for Community Health Centers (CHCs). To examine the role of Medicaid coverage on care patterns for those with available safety net care, we assessed differences in access to care for $\mathrm{CHC}$ patients with continuous Medicaid coverage vs. gaps in insurance coverage in the last year.

Methods: We used data on adult respondents from the 2014 Health Center Patient Survey $(N=1720)$ with continuous Medicaid coverage vs. those with some period without insurance coverage in the last 12 months. We examined reported need for any medical care, mental health care, prescription drugs, dental care, and referrals for care outside of the CHC in the last 12 months, and reports of being delayed or unable to get needed care by insurance status. We used logistic regression to assess the association between insurance status and care access, adjusting for patient characteristics.

Results: Patients with insurance gaps and continuous Medicaid coverage reported similar levels of need for most types of care in the last 12 months, but those with insurance gaps were significantly more likely to report having difficulty obtaining medical care, prescription drugs, dental care, and completing outside referrals. Of those with incomplete referrals for care outside of the $\mathrm{CHC}$, patients with insurance gaps were more likely than those with continuous Medicaid to cite cost or insurance-related reasons for not following up (70\% vs. 19\%, $p<0.01)$.
\end{abstract}

Conclusions: Having continuous Medicaid coverage appeared to mitigate barriers to care for CHC patients compared to having intermittent or no insurance coverage over the last year. Policies that increase disruptions in Medicaid coverage could adversely impact access to care, even among those with available safety net care.

Keywords: Medicaid, Uninsured, Community health centers, Safety-net, Access to care

\section{Background}

Increases in the availability of safety net care and insurance coverage could improve access to medical care for low-income populations. The Affordable Care Act (ACA) increased federal funding for Community Health Centers $(\mathrm{CHC})$, which provide care to underserved areas and populations, and also expanded Medicaid eligibility to adults with incomes less than $138 \%$ of the federal

\footnotetext{
* Correspondence: vfung@mgh.harvard.edu

'Health Policy Research Center, Mongan Institute, Massachusetts General Hospital, 100 Cambridge Street, Ste. 1600, Boston, MA 02114, USA

${ }^{3}$ Department of Medicine, Harvard Medical School, 25 Shattuck St, Boston, MA 02115, USA

Full list of author information is available at the end of the article
}

poverty level (FPL). To date, fourteen states have not yet adopted Medicaid expansion.

CHCs provided care to 27 million patients in 2017 and continue to be an important source of care post-ACA for low-income patients. Following Medicaid expansion, the share of $\mathrm{CHC}$ patients with Medicaid grew from 38 to $49 \%$ between 2010 and 2017 [1]. Some evidence suggests that gaining Medicaid coverage increases access to primary care and reduces financial barriers to care [2-4]. Studies have also found that there were greater increases in visits to $\mathrm{CHCs}$ and improvements in some measures of quality of care provided by CHCs after 2014 in states that expanded vs. did not expand Medicaid [5-7]. Less is

(c) The Author(s). 2019 Open Access This article is distributed under the terms of the Creative Commons Attribution 4.0 International License (http://creativecommons.org/licenses/by/4.0/), which permits unrestricted use, distribution, and reproduction in any medium, provided you give appropriate credit to the original author(s) and the source, provide a link to the Creative Commons license, and indicate if changes were made. The Creative Commons Public Domain Dedication waiver (http://creativecommons.org/publicdomain/zero/1.0/) applies to the data made available in this article, unless otherwise stated. 
known, however, about how having Medicaid coverage compared with no insurance influences care for patients with regular access to safety net care, such as CHCs, which provide care regardless of patients' ability to pay. In addition to primary care, many $\mathrm{CHCs}$ also provide mental health care, dental care, and substance use disorder treatment.

In this study, we used national survey data to examine access to different types of care for $\mathrm{CHC}$ patients in 2014, including medical care, mental health care, prescription drugs, dental services, and referrals for care outside of the health center. We compared access to care for those who were continuously covered by Medicaid vs. those with gaps in insurance coverage in the last year.

\section{Methods}

We used publicly available data from the 2014 Health Center Patient Survey (HCPS), a nationally representative survey of $\mathrm{CHC}$ patients sponsored by the Health Resources and Services Administration $(N=7002$; response rate $=$ 91.4\%) [8]. The HCPS was fielded in person at federally funded health centers between October 2014-April 2015 among patients with at least one prior visit to the $\mathrm{CHC}$ in the last 12 months. All data were deidentified and the study was exempted by the Institutional Review Board.

We limited our study to adult respondents $\geq 18$ years old seeking care at CHCs $(N=3172)$, excluding respondents seen at health centers serving specialty populations (i.e., Health Care for the Homeless, Migrant Health Centers, and Public Housing Primary Care; 9\% of the weighted sample of adult respondents). Because the survey measured care access in the 12 months prior to the time of the survey, we limited our Medicaid sample to those continuously enrolled in Medicaid for $\geq 12$ months $(N=750$; 69\% of respondents who reported having Medicaid at the time of the survey). To identify respondents who were uninsured for any period in the last 12 months, we included those who reported being uninsured at the time of the survey $(N=598)$ as well as those currently insured who reported being uninsured at some point in the last 12 months $(N=372)$. The HCPS did not collect information on the length of time respondents were uninsured.

Respondents reported if they needed any medical care, mental health care, prescription drugs, and dental care in the last 12 months, and, if so, whether they were delayed or unable to get the needed care. Additionally, respondents reported if they were referred for care outside of the $\mathrm{CHC}$ in the last 12 months, and, if so, whether they had followed up on their most recent referral. If respondents had not yet followed up, they were asked to select the main reason for the incomplete referral. We classified these reasons into three categories: cost/ insurance (e.g., could not afford care, insurance company would not approve/doctor would not accept/no insurance); logistics (e.g., no time off work, problems getting to appointment); and other. Among those with incomplete referrals, 63 respondents reported that their appointment was pending, still being scheduled, or that they were just referred at today's visit; we excluded these respondents from the analysis of incomplete referrals. Findings were similar in sensitivity analyses that included these respondents.

We compared the demographic and health characteristics of $\mathrm{CHC}$ patients with Medicaid to those who were uninsured for any period in the last 12 months, including patient age, gender, race/ethnicity, whether a language other than English was spoken at home, education, income, self-rated health status, disability status, and mental health status. The HCPS also included information on the urban/rural status of the respondents' $\mathrm{CHC}$ and whether the respondent reported the $\mathrm{CHC}$ to be their usual source of care. We determined disability status based on reported difficulty in six domains of functionality, using the Centers for Disease Control and Prevention's standard disability questions [9]. We determined mental health status by respondents' Kessler Psychological Distress Scale (K6) scores, with a score $\geq 13$ indicating a high degree of psychological distress [10].

We compared the percentage of respondents who reported needing the different types of services, and the percentage who reported having any difficulty obtaining that care for those with continuous Medicaid vs. insurance gaps. We used multivariate logistic regression models to examine the association between insurance status and difficulty obtaining care, adjusting for the patient characteristics described above. We applied sampling weights to account for the complex survey design.

\section{Results}

In this sample of $\mathrm{CHC}$ patients, the majority were female (68.1\%), had a high school education or less (65.2\%), and household income less than the federal poverty level (61.2\%). Nearly half reported being of non-White race/ ethnicity; those who were uninsured for any period in the last 12 months vs. those with continuous Medicaid coverage were more likely to be White $(46.4 \%$ vs. $52.4 \%)$ or Hispanic $(28.9 \%$ vs. $20.5 \%)$, and less likely to be Black (14.1\% vs. $25.5 \%, p<0.05$, Table 1 ). In addition, those who were uninsured vs. Medicaid-covered were more likely to speak a language other than English at home (32.0\% vs. 19.8\%) and visit $\mathrm{CHCs}$ in rural areas ( $52.4 \%$ vs. $36.8 \%, p<0.05)$.

Most respondents (81.7\%) in both groups reported that the $\mathrm{CHC}$ was their usual source of care. About $40 \%$ of both groups reported being in fair or poor health, having a functional disability, or had K6 scores indicating psychological distress; psychological distress was 
Table 1 Demographic and health traits by insurance status

\begin{tabular}{|c|c|c|c|c|}
\hline & Total $(N=1720)$ & $\begin{array}{l}\text { Continuous Medicaid coverage } \\
\text { last } 12 \text { months }(N=750)\end{array}$ & $\begin{array}{l}\text { Uninsured for any period in } \\
\text { last } 12 \text { months }(N=970)\end{array}$ & $p$-value \\
\hline \multicolumn{5}{|l|}{ Demographics } \\
\hline Age group & & & & 0.12 \\
\hline $18-44$ & 61.4 & 66.0 & 58.5 & \\
\hline $45-64$ & 37.7 & 32.9 & 40.8 & \\
\hline $65+$ & 0.9 & 1.1 & 0.7 & \\
\hline Male & 31.9 & 26.5 & 35.2 & 0.05 \\
\hline Race/ethnicity & & & & $<0.01$ \\
\hline White & 50.1 & 46.4 & 52.4 & \\
\hline Black & 18.5 & 25.5 & 14.1 & \\
\hline Asian & 1.8 & 2.6 & 1.3 & \\
\hline Hispanic & 25.7 & 20.5 & 28.9 & \\
\hline Other & 4.0 & 5.0 & 3.3 & \\
\hline Another language at home & 27.3 & 19.8 & 32.0 & $<0.01$ \\
\hline Education & & & & 0.63 \\
\hline < High School (HS) & 34.4 & 34.8 & 34.2 & \\
\hline HS or GED & 30.8 & 33.5 & 29.2 & \\
\hline$>\mathrm{HS}$ & 34.3 & 31.3 & 36.2 & \\
\hline Other & 0.4 & 0.4 & 0.4 & \\
\hline Household income & & & & 0.17 \\
\hline$\leq 100 \%$ of the Federal Poverty Level (FPL) & 61.2 & 66.9 & 57.6 & \\
\hline $101-138 \%$ FPL & 16.5 & 15.9 & 16.9 & \\
\hline 139-199\% FPL & 11.5 & 8.1 & 13.7 & \\
\hline $200 \%+F P L$ & 10.8 & 9.1 & 11.8 & \\
\hline Rural & 49.3 & 36.8 & 52.4 & $<0.01$ \\
\hline \multicolumn{5}{|l|}{ Health indicators } \\
\hline Health status & & & & 0.64 \\
\hline Excellent/Very good & 21.9 & 20.3 & 22.8 & \\
\hline Good & 36.7 & 39.2 & 35.1 & \\
\hline Fair/Poor & 41.5 & 40.4 & 42.1 & \\
\hline Disabled & 43.5 & 41.0 & 45.0 & 0.39 \\
\hline Psychological distress (K6 $\geq 13$ ) & 38.0 & 30.2 & 42.8 & $<0.01$ \\
\hline $\mathrm{CHC}$ is usual source of care & 81.7 & 81.9 & 81.6 & 0.94 \\
\hline \multicolumn{5}{|l|}{ Current insurance status } \\
\hline Medicaid & & 100.0 & 24.9 & \\
\hline Medicare or dual-eligible & & - & 1.2 & \\
\hline Private (group and non-group) & & - & 5.5 & \\
\hline Other/unspecified public or private & & - & 1.6 & \\
\hline Uninsured & & - & 66.8 & \\
\hline
\end{tabular}

Notes: Those uninsured for any period in the last 12 months include respondents who reported being uninsured at the time of the survey and currently insured respondents who reported being uninsured at any point in the last 12 months. Those with Medicaid include respondents who reported having Medicaid coverage in each of the last 12 months. The current insurance status distribution excludes respondents who answered "don't know" or refused to answer ( $0.1 \%$ of the uninsured sample)

more common among those with insurance gaps in the last 12 months vs. continuous Medicaid (42.8\% vs. $30.2 \%, \mathrm{p}<0.05)$. Among those who were uninsured sometime in the last 12 months, $33 \%$ were currently insured at the time of the survey, with Medicaid being the most common source of insurance (25\%). 
About two-thirds in both groups reported needing medical care in the last 12 months (Fig. 1). Reported needs for mental health care, prescription drugs, and referrals for care outside of the $\mathrm{CHC}$ were also similar between the groups.

Among those needing medical care, 27\% reported being delayed or unable to obtain care. Those uninsured in the last 12 months were more likely to report difficulties in obtaining medical care, prescription drugs, dental care, and outside referrals vs. those with continuous Medicaid coverage $(p<0.05$, Fig. 1$)$. Differences in obtaining needed mental health care were not significant. After adjusting for individual demographic and health traits, those with insurance gaps vs. continuous Medicaid were significantly more likely to have difficulty obtaining medical care, prescription drugs, and dental care, and to have not completed referrals for care outside of the $\mathrm{CHC}$ (Table 2).

Among those with incomplete referrals, $70 \%$ of those with insurance gaps, compared to $19 \%$ of those with continuous Medicaid, cited cost or insurance-related barriers as the main reason $(p<0.01$, Table 3$)$. Those with continuous Medicaid were more likely to cite logistical barriers as the reason.

\section{Discussion}

Among $\mathrm{CHC}$ patients, we found that those with continuous Medicaid coverage and those who were uninsured sometime in the last year had similar levels of need for most types of care. However, patients reporting disruptions in insurance coverage had greater difficulty obtaining care compared to those with continuous Medicaid coverage.
Table 2 Adjusted odds of reporting difficulty obtaining needed care for CHC patients who were uninsured for any period in last 12 months vs. patients continuously enrolled in Medicaid in the last 12 months

\begin{tabular}{lll}
\hline Type of care & Odds Ratio & $95 \% \mathrm{Cl}$ \\
\hline Delayed/unable to get medical care & 2.0 & $1.1-3.8$ \\
Delayed/unable to get mental health care & 1.6 & $0.7-3.6$ \\
Delayed/unable to get prescription drugs & 1.9 & $1.1-3.3$ \\
Delayed/unable to get dental care & 2.4 & $1.3-4.6$ \\
Did not follow up on most recent referral & 3.7 & $1.7-7.9$
\end{tabular}

Notes: Those uninsured for any period in the last 12 months include respondents who reported being uninsured at the time of the survey and currently insured respondents who reported being uninsured at any point in the last 12 months. Those with Medicaid include respondents who reported having Medicaid coverage in each of the last 12 months. Logistic regression models adjust for respondent demographic and health characteristics in Table 1. All analyses are weighted to account for the survey design

$\mathrm{CHC}$ revenues from Medicaid reimbursement have grown post-ACA. In addition, the ACA created the Community Health Center Fund (CHCF), which provided $\$ 11$ billion in mandatory funding for CHCs between 2011 and 2015 [11]. These funds accelerated recent growth in the number of health center delivery sites, staffing, and service provision; between 2011 and 2016, the number of CHC sites grew by $50 \%$ and the number of patients served by 33\% [12]. The CHCF, which now comprises $70 \%$ of federal funding for $\mathrm{CHCs}$, was recently reauthorized through the Bipartisan Budget Act of 2018, but only through 2019 [13].

All CHCs provide primary care services, with $89 \%$ providing mental health services, $81 \%$ providing dental services, and $35 \%$ providing substance use treatment in 2017 [1]. However, uninsured and Medicaid patients

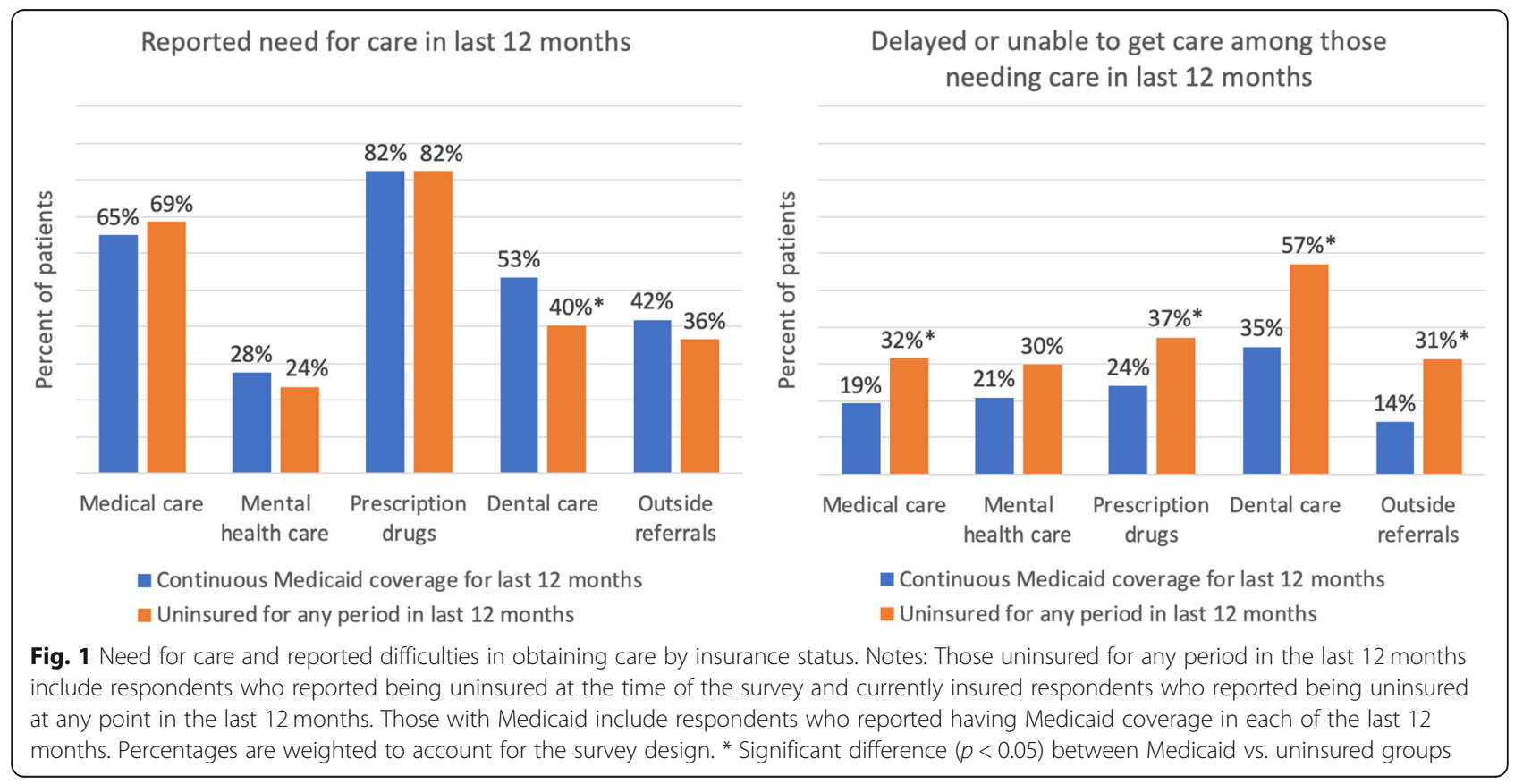


Table 3 Reasons for not following up on referral, by insurance status

\begin{tabular}{lll}
\hline & $\begin{array}{l}\text { Continuous Medicaid coverage } \\
\text { last 12 months }(N=34)\end{array}$ & $\begin{array}{l}\text { Uninsured for any period in } \\
\text { last 12 months }(N=90)\end{array}$ \\
\hline Cost/insurance barriers & $18.9 \%$ & $69.8 \%$ \\
Logistical barriers & $60.0 \%$ & $13.8 \%$ \\
Other & $21.1 \%$ & $16.4 \%$ \\
\hline
\end{tabular}

Notes: The number of respondents is unweighted; percentages are weighted to account for survey the design. Responses are reclassified into categories and exclude patients with pending appointments, who were waiting for the referral, needed to reschedule their appointment, or were referred at the time of the survey. Those uninsured for any period in the last 12 months include respondents who reported being uninsured at the time of the survey and currently insured respondents who reported being uninsured at any point in the last 12 months. Those with Medicaid include respondents who reported having Medicaid coverage in each of the last 12 months

seeking care at $\mathrm{CHCs}$ reported high levels of medical need and complexity, which necessitated referrals outside of the $\mathrm{CHC}$. Those with gaps in coverage were significantly less likely to complete these outside referrals compared to those with continuous Medicaid coverage, with most uninsured patients citing the cost of care or lack of insurance as the reason. Although the survey did not collect information on the specific type of care needed, these referrals are likely to be for specialty care not provided in the $\mathrm{CHC}$; forgoing such care may result in worse outcomes.

Notably, among those who were uninsured for some period in the last 12 months, nearly a quarter currently had Medicaid, but still faced greater difficulties accessing care compared to those with continuous Medicaid enrollment. In January 2018, the Centers for Medicare and Medicaid Services reversed guidance for Section 1115 waivers to allow states to impose work requirements as a condition for Medicaid eligibility. Fifteen states have submitted such waivers with seven approved as of April 2019 [14]. Some states are also including other provisions, such as increasing cost-sharing requirements or stipulating lock-out rules, which could impact Medicaid eligibility and increase the number of enrollees with disruptions in coverage. Our findings suggest that policies that increase Medicaid churn or disruptions in coverage could result in greater barriers for obtaining needed medical care, even among those with access to safety net care at CHCs.

This study has limitations. This is a cross-sectional study and there could be unmeasured confounding, although we were able to adjust for a number of sociodemographic and health-related traits. The comparison groups were similar with respect to a number of key traits, including age, education, household income, and health and functional status; however, those with gaps in insurance coverage were more likely to speak a non-English language at home, live in rural areas, and have psychological distress, which could contribute to additional barriers in accessing care.

The survey also did not capture how long respondents had gaps in insurance coverage or the reason for their lapse in coverage. The HCPS sample includes $\mathrm{CHC}$ patients with at least one prior visit and may not be generalizable to those who use $\mathrm{CHCs}$ more sporadically. We were not able to link patient responses with information on $\mathrm{CHC}$ service availability or whether respondents were directly affected by Medicaid expansion. Lastly, reasons for having difficulty obtaining care were only available for incomplete referrals, but not the other types of care in the survey.

\section{Conclusion}

There is continued debate about how best to provide and finance care for low-income Americans. Having continuous Medicaid coverage appeared to mitigate barriers to care among $\mathrm{CHC}$ patients compared to having intermittent or no insurance coverage, highlighting the complementary roles of the Medicaid and $\mathrm{CHC}$ programs for underserved populations. Policies that increase Medicaid churn could adversely impact access to care, even among those with available safety net care.

\section{Abbreviations \\ ACA: Affordable Care Act; CHC: Community Health Centers: \\ CHCF: Community Health Center Fund; HCPS: Health Center Patient Survey}

\section{Acknowledgements}

Not applicable.

\section{Funding}

This study was funded by the Agency for Healthcare Research and Quality under award R01HS02537 (Fung). The funding body was not involved in the design of the study, the collection, analysis, and interpretation of data, or in writing the manuscript.

Availability of data and materials

The datasets generated and/or analyzed during the current study are available from the Health Resources \& Services Administration, https://bphc. hrsa.gov/datareporting/research/hcpsurvey/index.html [1].

\section{Authors' contributions}

VS completed the analyses and drafted the manuscript. TPB contributed to the study design, data acquisition, and interpretation, and revised the manuscript for important intellectual content. ANT contributed to the study design and interpretation, and revised the manuscript for important intellectual content. PH contributed to the interpretation and revised the manuscript for important intellectual content. JPN contributed to the interpretation and revised the manuscript for important intellectual content. JH contributed to the interpretation and revised the manuscript for important intellectual content. VF conceived and supervised the study, contributed to the study design and interpretation, and drafted the manuscript. All the authors read and approved the final manuscript.

Ethics approval and consent to participate Not applicable.

Consent for publication

Not applicable. 


\section{Competing interests}

The authors declare that they have no competing interests.

\section{Publisher's Note}

Springer Nature remains neutral with regard to jurisdictional claims in published maps and institutional affiliations.

\section{Author details}

${ }^{1}$ Health Policy Research Center, Mongan Institute, Massachusetts General Hospital, 100 Cambridge Street, Ste. 1600, Boston, MA 02114, USA. ${ }^{2}$ Division of General Internal Medicine, Massachusetts General Hospital, 100 Cambridge St., Ste. 1600, Boston, MA 02114, USA. ${ }^{3}$ Department of Medicine, Harvard Medical School, 25 Shattuck St, Boston, MA 02115, USA. ${ }^{4}$ Institute for Research, Quality, and Policy in Homeless Health Care, Boston Health Care for the Homeless Program, 780 Albany St, Boston, MA 02118, USA. ${ }^{5}$ The Becker Friedman Institute, University of Chicago, 1126 E 59th St, Chicago, IL 60637, USA. ${ }^{6}$ Department of Health Care Policy, Harvard Medical School, 180 Longwood Ave, Boston, MA 02115, USA. 'Department of Health Policy and Management, Harvard T.H. Chan School of Public Health, 677 Huntington Ave, Boston, MA 02115, USA. ${ }^{8}$ Harvard Kennedy School, 79 John F. Kennedy Street, Cambridge, MA 02138, USA.

Received: 27 September 2018 Accepted: 24 April 2019

Published online: 08 May 2019

\section{References}

1. Sharac J, Shin P, Gunsalus R, et al. Community health centers continued to expand patient and service capacity in 2017. Policy issue brief (Geiger Gibson / RCHN Community Health Foundation Research Collaborative). Washington, D.C.: Milken Institute School of Public Health, George Washington University; 2018.

2. Baicker $\mathrm{K}$, Taubman $\mathrm{SL}$, Allen $\mathrm{HL}$, et al. The Oregon experiment - effects of Medicaid on clinical outcomes. N Engl J Med. 2013;368:1713-22.

3. Miller $S$, Wherry LR. Health and access to care during the first 2 years of the ACA Medicaid expansions. N Engl J Med. 2017:376:947-56.

4. Yue D, Rasmussen PW, Ponce NA. Racial/ethnic differential effects of Medicaid expansion on health care access. Health Serv Res. 2018;53:364056.

5. Cole MB, Wright B, Wilson IB, et al. Medicaid expansion and community health centers: care quality and service use increased for rural patients. Health affairs (Project Hope). 2018;37:900-7.

6. Hoopes MJ, Angier H, Gold R, et al. Utilization of community health centers in Medicaid expansion and nonexpansion states, 2013-2014. J Ambul Care Manage. 2016:39:290-8.

7. Cole MB, Galárraga O, Wilson IB, et al. At federally funded health centers, Medicaid expansion was associated with improved quality of care. Health Aff. 2017;36:40-8.

8. Health Resources \& Services Administration. 2014 Health Center Patient Survey data file user's manual 2016. Available at: https://bphc.hrsa.gov/ datareporting/research/hcpsurvey/2014usermanual.pdf. Accessed 18 Apr 2018

9. Centers for Disease Control and Prevention. Disability datasets. 2017. Available at: https://www.cdc.gov/ncbddd/disabilityandhealth/datasets.html. Accessed 18 Apr 2018

10. Kessler RC, Green JG, Gruber MJ, et al. Screening for serious mental illness in the general population with the K6 screening scale: results from the WHO world mental health (WMH) survey initiative. Int J Methods Psychiatr Res. 2010;19(Suppl 1):4-22.

11. The Community Health Center Fund: in brief. 2017. Available at: https:// www.everycrsreport.com/reports/R43911.html. Accessed 30 Apr 2018.

12. Paradise J, Rosenbaum S, Markus A, et al. Community health centers: recent growth and the role of the ACA. 2017. Available at: https://www.kff.org/ medicaid/issue-brief/community-health-centers-recent-growth-and-the-roleof-the-aca/. Accessed 18 Apr 2018.

13. Bipartisan Budget Act of 2018. House of Representatives; 2018.

14. Kaiser Family Foundation. Medicaid waiver tracker: which states have approved and pending section 1115 Medicaid waivers? 2018. Available at: https://www.kff.org/medicaid/issue-brief/which-states-have-approved-andpending-section-1115-medicaid-waivers/. Accessed 18 Apr 2019

\section{Ready to submit your research? Choose BMC and benefit from:}

- fast, convenient online submission

- thorough peer review by experienced researchers in your field

- rapid publication on acceptance

- support for research data, including large and complex data types

- gold Open Access which fosters wider collaboration and increased citations

- maximum visibility for your research: over $100 \mathrm{M}$ website views per year

At $\mathrm{BMC}$, research is always in progress.

Learn more biomedcentral.com/submissions 